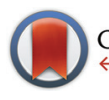

CrossMark

$\leftarrow$ click for updates

Cite this: Dalton Trans., 2016, 45

18838

Received 3rd November 2016,

Accepted 10th November 2016

DOI: 10.1039/c6dt04197c

www.rsc.org/dalton

\section{Boronic acid and boronic ester containing polyoxometalates $\uparrow$}

\author{
Hedi Karoui and Chris Ritchie*
}

Three organoboron functionalized polyoxometalates have been synthesized using Schiff base chemistry including a boronic acid, its methyl ester and its trimethylene glycol ester. The compounds have been characterized in the solid state by single crystal diffraction (XRD), FT-IR and elemental analysis and in solution using ${ }^{1} \mathrm{H}$ NMR spectroscopy.

Boronic acids have attracted the attention of chemists since the mid- $19^{\text {th }}$ century, largely due to their relatively straightforward preparation and chemical versatility. As precursors, boronic acids are particularly useful for the formation of $(\mathrm{C}-\mathrm{C})$ bonds via Suzuki Miyaura, Petasis, and Liebeskind-Srogl couplings, as well as the Chan-Lam coupling for the formation of (C-N and $\mathrm{C}-\mathrm{O}$ bonds). ${ }^{1-4}$ Further to these attractive cross coupling reactions, boronic acids can also be relatively easily condensed with a large range of substrates, as well as acting as strong Lewis acids. ${ }^{5}$ Consequently, an extensive library of molecules has been prepared from boronic acid precursors including pharmaceuticals, ${ }^{6,7}$ molecular cage compounds, crystalline covalent organic frameworks, ${ }^{8-12}$ polymers $^{13-15}$ and sensors. ${ }^{16-18}$ Despite this large and growing collection of molecules and materials, very few boronic acid containing inorganic-organic hybrids are known. ${ }^{19}$

Polyoxometalates (POMs) are a class of molecular metal oxides that possess notable structural and compositional versatility. The major structural components of POMs are typically assembled from the condensation of early transition metal oxyanions with the metal in high oxidation states, although this is by no means exclusive. One striking feature of these molecules is their ability to incorporate almost any element within their skeletal frameworks as heteroatoms, thus enabling further functionalization of the molecules, including the grafting of organic ligands. In POM chemistry, only a few

School of Chemistry, The University of Melbourne, Parkville, Melbourne, Victoria, 3010, Australia. E-mail: critchie@unimelb.edu.au

$\dagger$ Electronic supplementary information (ESI) available. CCDC 1496433-1496435. For ESI and crystallographic data in CIF or other electronic format see DOI: 10.1039/c6dt04197c molecular platforms exist that can be reliably utilized to yield predesigned molecules. For example, the routine and predictable surface modification of Lindqvist polyanions to yield organo-imido containing compounds, ${ }^{20-22}$ the insertion of organo-phosphate and silicate species into lacunary polyoxotungstate ligands $\mathrm{s}^{23-27}$ and the elaboration of the trisalkoxo functionalized Anderson-Evans POM by formation of imine and amide linkages. ${ }^{28-30}$

Herein, we report the first examples of organoboron containing Anderson-Evans POMs meshing the rich chemistries of these two important chemical classes. This initial report details the structures and characterization of the functionalized Mn(III) Anderson-Evans POM with the general formula $\left[\mathrm{Mn}(\mathrm{III}) \mathrm{Mo}_{6}(\mathrm{VI}) \mathrm{O}_{18}\left(\left(\mathrm{OCH}_{2}\right)_{3}\right) \mathrm{CN}=\mathrm{CHC}_{6} \mathrm{H}_{4}\left(\mathrm{~B}(\mathrm{OR})_{2}\right)_{2}\right]^{3-}, \quad$ where $\mathrm{R}=\mathrm{H}, \mathbf{1 a} ; \mathbf{M e}, \mathbf{1} \mathbf{b}$ and $\left[\mathrm{Mn}(\mathrm{III}) \mathrm{Mo}_{6}(\mathrm{VI}) \mathrm{O}_{18}\left(\left(\mathrm{OCH}_{2}\right)_{3}\right)\right.$ $\left.\mathrm{CN}=\mathrm{CHC}_{6} \mathrm{H}_{4}\left(\mathrm{BO}_{2}\left(\mathrm{CH}_{2}\right)_{3}\right)_{2}\right]^{3-}$, 1c. Bond valence sum calculations (BVS), confirm the assigned metal oxidation states with no evidence for protonation of the polyanion (Tables 1-3 in ESI $\dagger$ ). The three novel compounds are obtained through one pot synthesis. Mixing of 2-formylphenyl boronic acid with $(\mathrm{TBA})_{3}\left[\mathrm{Mn}(\mathrm{III}) \mathrm{Mo}_{6}(\mathrm{VI}) \mathrm{O}_{18}\left\{\left(\mathrm{OCH}_{2}\right)_{3} \mathrm{CNH}_{2}\right\}_{2}\right]$ at room temperature in dimethylformamide (DMF) results in the crystallisation of 1a through slow evaporation, with the addition of 1,3 propanediol to the same reaction mixture resulting in the crystallization of 1c on vapour diffusion of diethyl ether. A pure microcrystalline sample of $\mathbf{1 b}$ is obtained when the reaction is conducted in methanol, with recrystallization from DMF yielding crystals suitable for single crystal X-ray diffraction. All crude products were thoroughly washed with cold methanol then diethyl ether to remove residual starting materials.

Compound 1a (Fig. 1a, left) crystallizes in the monoclinic space group $I 2 / a$ with cell axes $a=24.0713(6), b=14.3578(5)$, $c=28.5472(15)$ where $\beta=94.407(3)^{\circ}$ and $V=9837.1(7) \AA$ with half a polyanion in the asymmetric unit. The molecular structure of 1a shows the expected coordination of the tripodal ligand to the surface of the polyanion as observed in the starting material (TBA $)_{3}\left[\mathrm{Mn}(\mathrm{III}) \mathrm{Mo}_{6}(\mathrm{VI}) \mathrm{O}_{18}\left\{\left(\mathrm{OCH}_{2}\right)_{3} \mathrm{CNH}_{2}\right\}_{2}\right]$. Condensation of the di-amino terminated precursor with 2-formylphenylboronic acid results in the formation of the anti- 


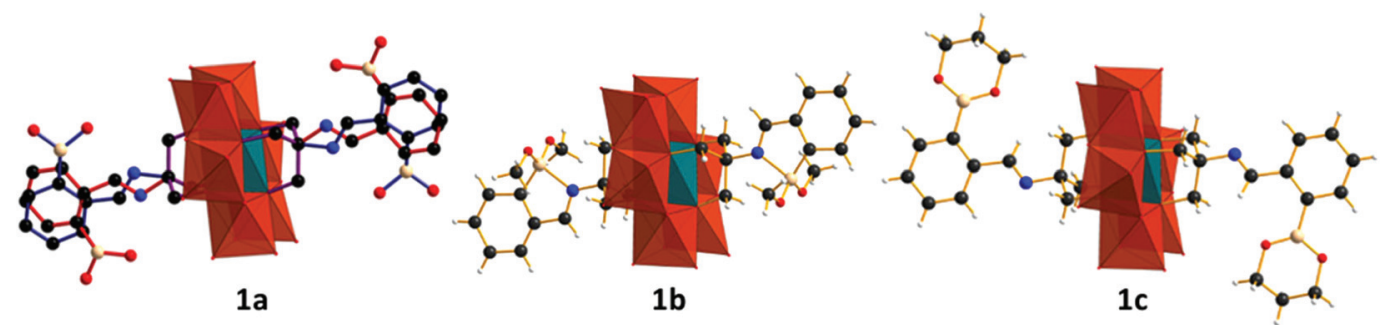

Fig. 1 Representation of compounds $1 \mathrm{a}-\mathrm{c}$ from left to right. Crystallographic disorder of $1 \mathrm{a}$ is clarified by the use of red and blue bonds. MoO orange polyhedra; $\mathrm{MnO}_{6}$, teal polyhedra; $\mathrm{C}$, black spheres; $\mathrm{O}$, red spheres; $\mathrm{N}$, blue spheres; $\mathrm{B}$, beige spheres; $\mathrm{H}$, white spheres.

cipated secondary aldimine as confirmed by single-crystal X-ray diffraction, IR (S1) and ${ }^{1} \mathrm{H}$ NMR studies (S4). Unfortunately, significant crystallographic disorder of the grafted ligand is observed which prevented accurate determination of bond lengths and angles, with a significant number of crystallographic restraints being imposed to satisfactorily refine the disorder. The aldimine nitrogen refines well over two positions as does the remainder of the ligand with thermal parameters suggesting $1: 1$ occupancy of the two crystallographic positions. Refinement of the aromatic portion of the ligand indicates rotational disorder, with two positions for the boronic acid functional group being identified with approximately equal contributions using the FVAR command. Subsequently the two disordered positions were fixed with equal occupancies. Intramolecular interactions include $\mathrm{N}-\mathrm{H}-$ $\mathrm{O}-\mathrm{B}$ hydrogen bonding between the aldimine nitrogen and the protons of the boronic acid, with intermolecular hydrogen bonding between the boronic acid functional groups of neighbouring molecules resulting in supramolecular ribbons in the solid state. Disorder of the TBA cations and solvent required the use of a solvent mask, with the composition and bulk purity of 1a verified by combustion. The solution state structure of 1a was also probed using ${ }^{1} \mathrm{H}$ in $\mathrm{d}_{6}$-DMSO and is discussed in detail later.

Compound 1b (Fig. 1, middle) crystallizes in the monoclinic space group $P 2_{1} / c$ with cell axes $a=22.8863(8), b=24.7348(7)$ and $c=18.1665(6)$ where $\beta=93.009(3)^{\circ}$ and $V=10269.7(6)$ with two crystallographically independent halves of the functionalised cluster residing in the asymmetric unit. Reaction of (TBA $)_{3}\left[\mathrm{Mn}(\mathrm{III}) \mathrm{Mo}_{6}(\mathrm{VI}) \mathrm{O}_{18}\left\{\left(\mathrm{OCH}_{2}\right)_{3} \mathrm{CNH}_{2}\right\}_{2}\right]$ with 2-formylphenylboronic acid in methanol yields the boronate methyl ester functionalized polyanion $\mathbf{1 b}$ (Fig. 1, middle). Crystallographic analysis of $\mathbf{1 b}$ shows an intramolecular $\mathrm{B}-\mathrm{N}$ dative bond between the aldimine nitrogen and the boron of the boronate methyl ester with a bond length of 1.830(4) A. The formation of which is facilitated by the conversion of the boronic acid to its methyl ester, negating the possibility of intramolecular hydrogen bonding between the aldimine nitrogen lone pair and the protons of the boronic acid as observed in 1a (Fig. 2). As a result of the $\mathrm{B}-\mathrm{N}$ dative bond, the boron bonding is distorted from idealized $C 3$ symmetry expected for $\mathrm{sp}^{2}$ hybridization, to that lying between trigonal and tetrahedral. Bond lengths and angles are summarized in Table 4 in ESI. $\dagger$ The

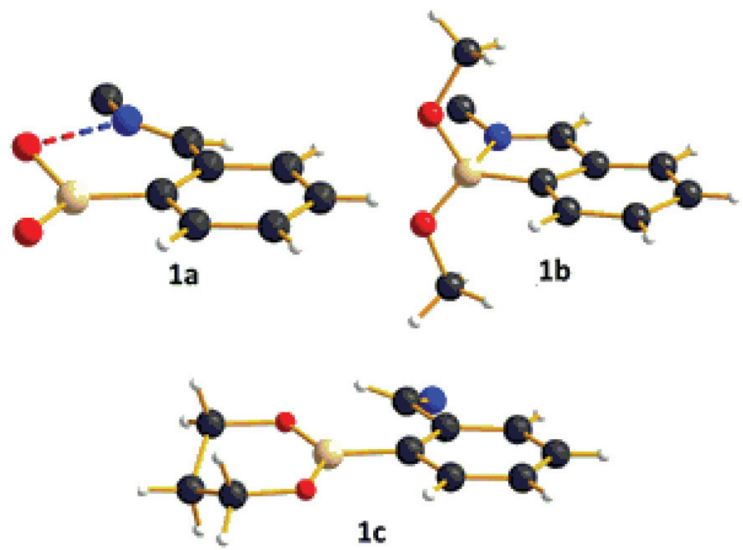

Fig. 2 Ball and stick representation of the different boron nitrogen environments in the boronic acid and boronic ester moieties of $1 \mathrm{a}, 1 \mathrm{~b}$ and $1 \mathrm{c}$. $\mathrm{C}$, black spheres; $\mathrm{O}$, red spheres; $\mathrm{N}$, blue spheres; $\mathrm{B}$, beige spheres; $\mathrm{H}$, white spheres.

extended structure of $\mathbf{1 b}$ includes intermolecular $\mathrm{C}-\mathrm{H} \cdots \pi$ hydrogen bonds between the methyl protons of the $\left\{\mathrm{B}(\mathrm{OMe})_{2}\right\}$ moiety and the aromatic system of neighbouring functionalized molecules, resulting in the formation of 1D supramolecular chain structures. A more extensive discussion regarding the crystallographic disorder of the polyanions can be found in the ESI. $\dagger$

The ability of boron to form reversible covalent complexes with vicinal 1,2 and 1,3 diols prompted us to probe this chemistry. Stoichiometric addition of 1,3 propane-diol to the reaction mixture which would otherwise yield 1a, results in the almost quantitative crystallization of $\mathbf{1} \mathbf{c}$ where the boronic acid has been converted to its trimethylene glycol ester. 1c crystallizes in the monoclinic space group $C 2 / c$ with cell axes $a=$ 35.796(3), $b=13.2361$ (3) and $c=25.8822(19)$ where $\beta=128.966$ $(12)^{\circ}$ and $V=9534.7(19)$ with one-half of the functionalized cluster residing in the asymmetric unit. As with 1a, no intramolecular interactions between the aldimine nitrogen and boron are observed in the solid state. This is due to unfavourable steric interactions between the glycol ester and the POM surface. Crystallographic data for compounds $\mathbf{1 a}, \mathbf{1 b}$ and $\mathbf{1 c}$ are summarized in Table 5 in ESI. $\dagger$ The IR spectra of 1a-c $(\mathbf{S 1}, \mathbf{S 2}$ and S3) feature characteristic vibrational bands between 
890-950 $\mathrm{cm}^{-1}$ for the terminal $\mathrm{Mo}=\mathrm{O}$ units and between 660 and $710 \mathrm{~cm}^{-1}$ for the bridging Mo-O-Mo groups of the tris functionalized Mn-Anderson. Additional boronate stretches are observed between 1350-1380 and 1430-1460 $\mathrm{cm}^{-1}$ with the vibrational band located between $2800-3000 \mathrm{~cm}^{-1}$ assigned to the aldimine functionality.

Attempts to collect ${ }^{13} \mathrm{C}$ and ${ }^{11} \mathrm{~B}$ NMR spectra were unsuccessful due to the presence of the paramagnetic $\mathrm{Mn}^{\text {III }}$ ion located at the centre of the polyanion, meanwhile all ${ }^{1} \mathrm{H}$ resonances show significant broadening (Fig. 3).

Spectroscopic analysis of 1a-b using ${ }^{1} \mathrm{H}$ NMR (S4 and S5) supports the crystallographic observations. The ${ }^{1} \mathrm{H}$ NMR of 1a shows broad signals at $\delta=7.20,7.48,7.63,8.33$ and $8.48 \mathrm{ppm}$ with the anticipated integrations of $1: 1: 2: 2: 1$. The strongly deshielded $\left(\mathrm{OCH}_{2}\right)$ protons are also observed at $\delta=62.96 \mathrm{ppm}$ due to their proximity to the $\mathrm{Mn}^{\mathrm{III}}$ center. Residual signals are observed in the aromatic region between 7.8-8 ppm due to 2-formylphenyl boronic acid starting material, meanwhile no changes were observed over time suggesting stability in solution.

On dissolution of a freshly prepared sample of $\mathbf{1 b}$ a very similar ${ }^{1} \mathrm{H}$ NMR spectrum is obtained indicating that the solid state $\mathrm{B}-\mathrm{N}$ interaction is not maintained in solution. Furthermore, the methyl ester protons are not observed, with additional resonances at $3.14 \mathrm{ppm}$ indicating partial hydrolysis of the boronic methyl ester releasing 1 equivalent of methanol. The study of B-N dative bond dynamics and the calculation of
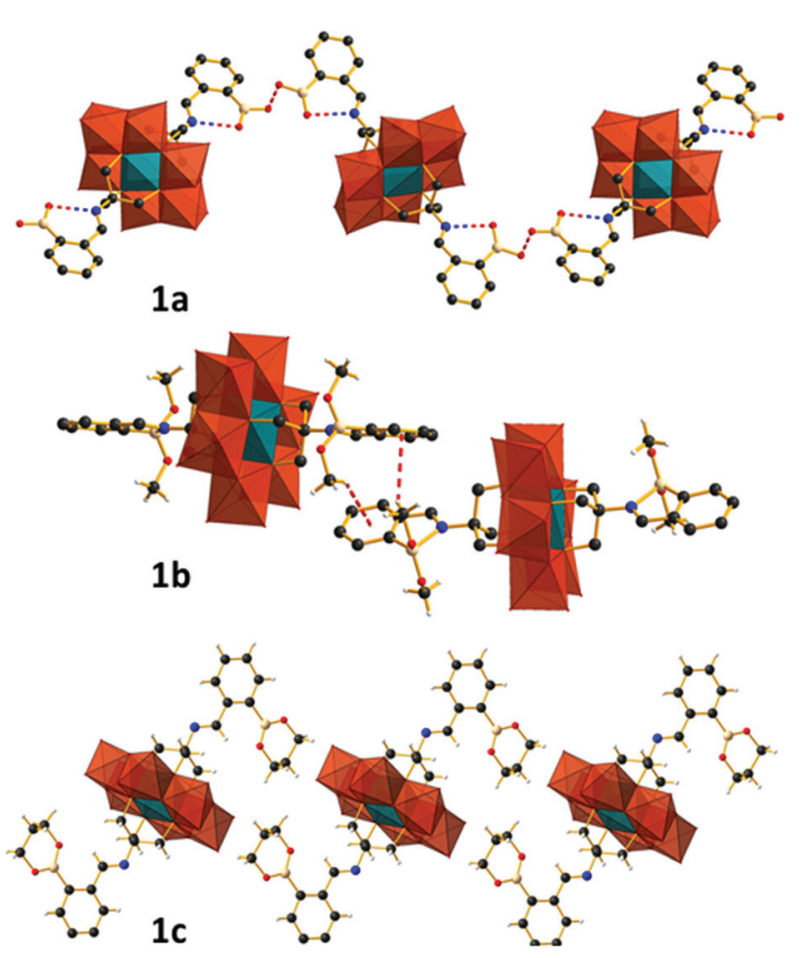

Fig. 3 Representation of the intra and intermolecular interactions for $1 \mathrm{a}$ - top, $1 \mathrm{~b}$ - middle and $1 \mathrm{c}$ - bottom. $\mathrm{MoO}_{6}$, orange polyhedra; $\mathrm{MnO}_{6}$, teal polyhedra; $\mathrm{C}$, black spheres; $\mathrm{O}$, red spheres; $\mathrm{N}$, blue spheres; $\mathrm{B}$, beige. activation parameters for nitrogen inversion are typically investigated using variable temperature VT-NMR and $a b$ initio calculations with correlation to ${ }^{11} \mathrm{~B}$ NMR and crystallographic data. ${ }^{31}$ Using the same techniques it is also possible to probe the effect of solvents on the boron environment due to the applicability of boronic acids in molecular sensors. ${ }^{32}$ Unfortunately, the presence of the paramagnetic Mn(III) ion in 1a-1c precluded the possibility of these experiments on this particular system. We are currently developing a series of diamagnetic POM based molecules that will be investigated using these approaches.

${ }^{1} \mathrm{H}$ NMR of compound 1c shows overlapping of diol-boronic acid functionalized POMs and boronic acid functionalized POMs peaks in the aromatic region suggesting partial hydrolysis of the diol-boronic acid complex in $\mathrm{d}_{6}$-DMSO. This was confirmed by the observation of two sets of peaks, one broad peak at $3.99 \mathrm{ppm}$ corresponding to the boronic acid bonded methylene glycol in the functionalized POM and a triplet at $4.32 \mathrm{ppm}$ corresponding to the free propanediol in solution. Hydrolysis of the imine linkage was also observed with a supplementary aldehyde singlet observed at $10.33 \mathrm{ppm}$ and diolboronic acid triplet at $4.11 \mathrm{ppm}$. To quantify the hydrolysis of imine linkage, titration experiments with propanediol were undertaken. Upon addition of $0.5 \mathrm{eq}$. of propanediol to 1a, two sets of $\left(\mathrm{OCH}_{2}\right)$ peaks at $61.68 \mathrm{ppm}$ and $63.59 \mathrm{ppm}$ were observed corresponding respectively to a mixture of $\mathbf{1 c}$ and $\left[\mathrm{Mn}(\mathrm{III}) \mathrm{Mo}_{6}(\mathrm{VI}) \mathrm{O}_{18}\left\{\left(\mathrm{OCH}_{2}\right)_{3} \mathrm{CNH}_{2}\right\}_{2}\right]^{3-}$ in the ratio $2.5: 1$ (S8). This ratio decreases to reach $1: 6$ upon addition of 2 eq. propanediol (S9) and 1:13 upon addition of 4 eq. propanediol (S10). The methylene protons of the boronate ester 1c appear at $4.03 \mathrm{ppm}$ on addition of 0.5 eq. propanediol to a solution of 1a. At this ratio, the methylene protons integrate as $2: 1$ with respect to the aromatic resonances indicating $50 \%$ of $1 \mathrm{a}$ has been converted to 1c. On adding sequential aliquots of propanediol, the resonance at $4.03 \mathrm{ppm}$ diminishes, finally disappearing after addition of 4 eq. indicating complete imine hydrolysis (S8-S10).

We have successfully coupled 2-formylphenyl boronic acid to the Mn-Anderson platform using Schiff base chemistry, and additionally investigated the conversion of the boronic acid functionality to the corresponding methyl and trimethylene glycol esters. As anticipated, these species display a degree of hydrolytic instability in solution, yet they can be readily obtained as solid state structures. Transfer of these species into non-polar solvents is underway as are investigations into their structural elaboration using the boronic acid functional group. Furthermore, hydrolytically stable and diamagnetic derivatives are currently in preparation and will be reported in due course.

\section{Notes and references}

1 N. Miyaura and A. Suzuki, Chem. Soc. Rev., 1995, 95(7), 2457-2483.

2 N.-A. Petasis and I. Akritopoulou, Tetrahedron Lett., 1993, 34, 583-586. 
3 L. S. Liebeskind and J. Srogl, J. Am. Chem. Soc., 2000, 122, 11260-11261.

4 D. Chan, K. Monaco, R. Wang and M. Winter, Tetrahedron Lett., 1998, 39, 2933-2936.

5 D. Salazar-Mendoza, J. Cruz-Huerta, H. Höpfl, I. F. Hernández-Ahuactzi and M. Sanchez, Cryst. Growth Des., 2013, 13(6), 2441-2454.

6 N. Iwasawa, H. Takahagi, K. Ono, K. Fujii and H. Uekusa, Chem. Commun., 2012, 48, 7477-7479.

7 N. Christinat, R. Scopelliti and K. Severin, Chem. Commun., 2008, 3660-3662.

8 N. Christinat, R. Scopelliti and K. Severin, Angew. Chem., Int. Ed., 2008, 47, 1848-1852.

9 J. Hunt, C. Doonan, J. LeVangie, A. Côté and O. Yaghi, J. Am. Chem. Soc., 2008, 130, 11872-11883.

10 N. Christinat, R. Scopelliti and K. Severin, Chem. Commun., 2008, 31, 3660-3662.

11 N. Christinat, R. Scopelliti and K. Severin, J. Org. Chem., 2007, 72, 2192-2200.

12 A. Côté, H. El-Kaderi, H. Furukawa, J. Hunt and O. Yaghi, J. Am. Chem. Soc., 2007, 129, 12914-12915.

13 T. D. James, K. R. A. S. Sandanayake and S. Shinkai, Angew. Chem., Int. Ed. Engl., 1996, 35(17), 1910-1922.

14 Z. Guo, I. Shin and J. Yoon, Chem. Commun., 2012, 48, 5956-5967.

15 G. Mirri, S. Bull, P. Horton, T. James, L. Male and J. Tucker, J. Am. Chem. Soc., 2010, 132, 8903-8905.

16 Y. Zhu, Z. Xiao, N. Ge, N. Wang, Y. Wei and Y. Wang, Cryst. Growth Des., 2006, 6, 1620-1625.

17 J. Zhang, F. Xiao, J. Hao and Y. Wei, Dalton Trans., 2012, 41, 3599-3615.

18 G. Sima, Q. Li, Y. Zhu, C. Lu, R. N. Khan, J. Hao, J. Zhang and Y. Wei, Inorg. Chem., 2013, 52, 6551-6558.

19 J. Cambre, D. Roy, S. Gondi and B. Sumerlin, J. Am. Chem. Soc., 2007, 129, 10348-10349.

20 M. Healey, S. Best, L. Goerigk and C. Ritchie, Inorganics, 2015, 3(2), 82-100.
21 N. Joo, S. Renaudineau, G. Delapierre, G. Bidan, L.-M. Chamoreau, R. Thouvenot, P. Gouzerh and A. Proust, Chem. - Eur. J., 2010, 16(17), 5043-5051.

22 A. Proust, R. Thouvenot and P. Gouzerh, Chem. Commun., 2008, 1837-1852.

23 C. Dablemont, A. Proust, R. Thouvenot, C. Afonso, F. Fournier and J.-C. Tabet, Inorg. Chem., 2004, 43, 35143520 .

24 S. Bareyt, S. Piligkos, B. Hasenknopf, P. Gouzerh, E. Lacôte, S. Thorimbert and M. Malacria, J. Am. Chem. Soc., 2005, 127, 6788-6794.

25 C. Boglio, K. Micoine, É. Derat, R. Thouvenot, B. Hasenknopf, S. Thorimbert, E. Lacôte and M. Malacria, J. Am. Chem. Soc., 2008, 130, 4553-4561.

26 B. Matt, S. Renaudineau, L.-M. Chamoreau, C. Afonso, G. Izzet and A. Proust, J. Org. Chem., 2011, 76, 31073112.

27 J. Li, I. Huth, L.-M. Chamoreau, B. Hasenknopf, E. Lacôte, S. Thorimbert and M. Malacria, Angew. Chem., Int. Ed., 2009, 48, 2035-2038.

28 C. Allain, S. Favette, L. Chamoreau, J. Vaissermann, L. Ruhlmann and B. Hasenknopf, Eur. J. Inorg. Chem., 2008, 22, 3433-3441.

29 D. Schaming, C. Allain, R. Farha, M. Goldmann, S. Lobstein, A. Giraudeau, B. Hasenknopf and L. Ruhlmann, Langmuir, 2010, 26, 5101-5109.

30 C. Yvon, A. Surman, M. Hutin, J. Alex, B. O. Smith, D.-L. Long and L. Cronin, Angew. Chem., Int. Ed., 2014, 53, 3336-3341.

31 C. Hoang, I. Prokes, G. Clarkson, M. Rowland, J. Tucker, M. Shipman and T. Walsh, Chem. Commun., 2013, 49, 2509-2525.

32 (a) L. Zhu, S. H. Shabbir, M. Gray, V. M. Lynch, S. Sorey and E. V. Anslyn, J. Am. Chem. Soc., 2006, 128, 1222; (b) B. E. Collins, S. Sorey, A. E. Horgrove, S. H. Shabbir, V. M. Lynch and E. V. Anslyn, J. Org. Chem., 2009, 74, 4055 . 